\title{
SABotaging Potential Rivals
}

\author{
J. Atsu AMEGASHIE \\ MARCO RUNKEL
}

\author{
CESIFo Working PAPER No. 1500 \\ CATEgory 2: Public CHOICE \\ JULY 2005 \\ Presented at CESifo Area Conference on
Public SeCtor ECONOMics, April 2005
}
An electronic version of the paper may be downloaded
- from the SSRN website: Www.SSRN.com
- from the CESifo website: www.CESifo.de




\title{
SABotaging Potential Rivals
}

\begin{abstract}
This paper studies sabotage in a contest with non-identical players. Unlike previous papers, we consider sabotage in an elimination contest and allow contestants to sabotage a potential or future rival. It turns out that for a certain partition of players there is a pure-strategy equilibrium in which only the most able contestant engages in sabotage while less able contestants do not. The most able contestant may therefore prefer a situation where sabotage is allowed to one where sabotage is not allowed. For another partition of players, there is a unique equilibrium in which none of the players invests in sabotage.
\end{abstract}

JEL Code: D72, D74.

Keywords: all-pay auction, elimination contests, potential rival, sabotage.

J. Atsu Amegashie
Department of Economics
University of Guelph
Guelph, Ontario
Canada N1G 2W1
jamegash@uoguelph.ca

\author{
Marco Runkel \\ Department of Economics \\ University of Munich \\ Ludwigstr. 28, Vgb., III \\ 80539 Munich \\ Germany \\ marco.runkel@Irz.uni-muenchen.de
}

We thank participants of the 2005 Annual Meeting of the Public Choice Society in New Orleans and participants of seminars at the Universities of Munich and Waterloo for helpful comments, especially John Burbidge, Lutz-Alexander Busch, and Frank Westermann. 


\section{Introduction}

In contests like political competitions, rent-seeking or R\&D races, a contestant basically has two options to increase her probability of success. She can spend effort to improve her own performance and/or effort that reduces a particular rival's performance. The latter effort is usually understood as sabotage. There is a growing and interesting literature on sabotage or negative activities in contests and organizations, for example Auriol et al. (2003), Chen (2003), Konrad (2000), Kräkel (2004), Lazear (1989), and Skarpedas and Grofman (1995). The authors characterize equilibria in contests with sabotage and compare them with the equilibria when sabotage is not possible.

All these articles investigate single-stage contests ${ }^{1}$ and, thus, necessarily focus on sabotage of current opponents. But contestants sometimes have incentives to sabotage potential or future rivals. Chen (2003, footnote 1$)$ observes that "[o]ne example in U.S. politics is Mario Cuomo, ex governor of New York. For many years, he had been considered a top contender for the U.S. presidency, but he eventually faded from the scene. Simply, too many people had seen him as a potential rival.” (italics ours). A similar example is Howard Dean. For a long time, he was seen a top candidate of the Democrats in the 2004 U.S. presidential election. One may even argue that he would have been the stronger rival for the Republican candidate George Bush, since he was a strong opponent of the Iraq war, while the actual candidate of the Democrats, John Kerry, was titled a "Flip-Flopper" with respect to the Iraq war. But during the primaries of the Democrats in autumn 2003, several negative reports of Bush-friendly media appeared and

\footnotetext{
${ }^{1}$ Kräkel (2004) examines a two-stage game but not a two-stage contest. In his model, the contest for the prize only takes place in stage 2 . In our model, the contest for the prize takes place in two stages.
} 
reduced the chance of Dean to become the candidate of the Democrats. ${ }^{2}$ Further examples for sabotage of potential rivals can be found in TV game shows like "The weakest Link", "Survivor" and "Big Brother".

Motivated by these examples, this paper investigates sabotage of potential rivals. We develop a two-stage elimination contest model with four players who differ in the valuation of winning the contest. In the first stage, the players are grouped in two semifinals. The winners of the semi-finals advance to the second stage, the final. Both stages are modeled as all-pay auctions. Sabotage is incorporated in the model by assuming that before the elimination contest each contestant can decide whether she will help the weaker player in the other semi-final. One may argue that this support should be called a "subsidy" instead of "sabotage". We prefer to use the term (indirect) sabotage because although a player indeed subsidizes a weaker player in another group, the main goal of the subsidy is to weaken the stronger player's chances of advancing to the next stage. ${ }^{3}$

In this setting, we find that for a certain partition of players there is a purestrategy equilibrium in which only the most able contestant engages in sabotage while less able contestants do not. We also find that the most able contestant may prefer a situation where sabotage is allowed to one where sabotage is not allowed. For another

\footnotetext{
${ }^{2}$ Of Course, it is difficult to say whether Dean did not succeed because he was "sabotaged" by supporters of Bush or because he did not find enough supporters among the Democrats. Dean himself states that he was sabotaged. See his interview regarding the "The Scream" at the webpage http://www.crocuta.net/Dean/ Dean Interview NHPR June29 2004.htm. Moreover, it is interesting to note that there were discussions among Bush supporters whether it is a suitable option "...to sabotage the opposing party's primary to ensure the nomination of the worst candidate possible" (http://www.pejmanesque.com/archives/003745.html).

${ }^{3}$ In our model, this indirect sabotage is indeed equivalent to directly sabotaging the future rival. We use the indirect modeling since it is often observed in reality. For example, in the 2004 U.S. election campaign traditional Republican campaign contributors simultaneously contributed to Ralph Nader (an independent candidate) and George Bush. The contribution to Ralph Nader is to ensure that he draws away some votes from the Democratic candidate, John Kerry. Hence the Republicans indirectly sabotaged John Kerry through a third party, Ralph Nader. We wish to emphasize that this is an example of indirect sabotage. It is not an example of sabotaging a potential rival.
} 
partition of players, there is a unique equilibrium in which none of the players engages in sabotage.

Note that our model is based on the elimination contest in Groh et al. (2003). We introduce the sabotage of potential rivals in their model. However, our main focus is different. In an elimination contest without sabotage and four contestants, Groh et al. (2003) compare different partitions of contestants based on the following three criteria:

(i) maximization of total productive effort in the contest, (ii) maximization of the probability of a final among the two top players, and (iii) maximization of the win probability for the top player. They also compare the partitions with respect to the property that a higher ranked player has a higher win probability. In contrast, we focus mainly on the sabotage incentives of the contestants under different partitions.

The paper is organized as follows: the next section sets up the general model. In Section 3, we derive equilibria for specific partitions of players. Section 4 discusses our results and explains in more detail the relation to results obtained in previous sabotage models. Section 5 concludes.

\section{Indirect Sabotage in an Elimination Contest}

We consider a two-stage elimination contest as in Groh et al. (2003). ${ }^{4}$ However, unlike Groh et al. (2003), we introduce a pre-contest stage where players can decide to indirectly sabotage potential rivals. The contest is among four players labeled by $1,2,3$, and 4 . The timing of actions is as follows: In stage 0 , players decide how much sabotage effort to expend. In stage 1 (the semi-finals), two players are put in a group in an all-pay auction

\footnotetext{
${ }^{4}$ For other papers on elimination contests, see Amegashie (1999, 2004), Gradstein and Konrad (1999) and Rosen (1986).
} 
where their valuations are their post-sabotage valuations. The winner in each group advances to stage 2 (the final), where the overall winner of the contest is determined again by an all-pay auction.

We call the efforts in the all-pay auctions on stage 1 and 2 "productive effort". They are directly productive in the sense that a possible contest-designer puts a positive value on them. For example, in a sales contest, these efforts will be sales per contestant. But the sabotage effort in stage 0 is directly "unproductive" because the contest designer does not value this effort. Note, however, that we only focus on the positive implications of sabotage and do not discuss the optimal design of our contest.

Our equilibrium concept is subgame perfection. We look for a subgame perfect equilibrium of our game by backward induction. We begin with stage 2: Denote the two finalists by $i, j \in\{1,2,3,4\}$ with $i \neq j$. The finalists expend productive effort $e_{i f} \geq 0$ and $e_{j f} \geq 0$ in hope of winning the prize. Players $i$ and $j$ valuations of the prize are $V_{i}$ and $\mathrm{V}_{\mathrm{j}}$, respectively. Unless otherwise indicated, we assume that $\mathrm{V}_{1}>\mathrm{V}_{2}>\mathrm{V}_{3}>\mathrm{V}_{4}>0$ and these valuations are commonly known by all contestants. The prize is awarded to the player with the higher effort. In case both efforts are the same, each finalist receives the prize with probability $1 / 2$. As in Groh et al. (2003), the finalists in stage 2 additionally receive a payment of $\mathrm{k}>0$, regardless of their effort in this stage. ${ }^{5}$ Hence, for $\mathrm{e}_{\mathrm{if}}>\mathrm{e}_{\mathrm{jf}}$, player i's payoff in the final is $\mathrm{V}_{\mathrm{i}}+\mathrm{k}-\mathrm{e}_{\mathrm{if}}$. If $\mathrm{e}_{\mathrm{if}}<\mathrm{e}_{\mathrm{jf}}$, then she receives $\mathrm{k}-\mathrm{e}_{\mathrm{if}}$ and in

\footnotetext{
${ }^{5}$ As pointed out in Groh et al. (2003), “... this is a necessary condition for the existence of equilibria in the semi-finals". Otherwise, there are, at least, two players whose valuations in the semi-finals are zero. These players will exert no effort in the semi-finals. But then a pure-strategy effort of zero is not an equilibrium strategy.
} 
case of $e_{i f}=e_{j f}$, her payoff is $V_{i} / 2+k-e_{i f}$. The payoff of player $\mathrm{j}$ is computed in the same way.

It is well known that the equilibrium effort levels in such an all-pay auction are in mixed strategies. Based on results in Baye et al. (1996) and Hillman and Riley (1989), we can write the expected payoffs of player $i$ and $j$ in this equilibrium respectively as

$$
\Pi_{2}(\mathrm{i}, \mathrm{j})=\max \left\{\mathrm{V}_{\mathrm{i}}-\mathrm{V}_{\mathrm{j}}, 0\right\}+\mathrm{k}, \quad \Pi_{2}(\mathrm{j}, \mathrm{i})=\max \left\{\mathrm{V}_{\mathrm{j}}-\mathrm{V}_{\mathrm{i}}, 0\right\}+\mathrm{k} \text {. }
$$

If $V_{i} \geq V_{j}$, the equilibrium winning probabilities of player $i$ and $j$ are $p_{i 2}=1-V_{j} / 2 V_{i}$ and $\mathrm{p}_{\mathrm{j} 2}=1-\mathrm{p}_{\mathrm{i} 2}$, and equilibrium total expected effort amounts to $\mathrm{V}_{\mathrm{j}}\left(1+\mathrm{V}_{\mathrm{j}} / \mathrm{V}_{\mathrm{i}}\right) / 2$. In case of $V_{i} \leq V_{j}$, we simply have to exchange the indices $i$ and $j$ in order to obtain the equilibrium winning probabilities and equilibrium total effort. For a given partition of players, the equilibrium in stage 2 is unique (see, Baye et al., 1996).

Let us now formalize stage 1 . We denote the players in one semi-final by $\mathrm{h}, \ell \in\{1,2,3,4\}$ and in the other semi-final by $\mathrm{m}, \mathrm{n} \in\{1,2,3,4\}$ where $\mathrm{h} \neq \ell \neq \mathrm{m} \neq \mathrm{n}$. Both semi-finals are all-pay auctions. To account for indirect sabotage, we assume that the valuation of a player in stage 1 is increased by the effort which other players expend in stage 0 in order to help this player and to indirectly sabotage potential rivals. This support can be interpreted as, e.g., an extra payment which the supported player receives or as a cost subsidy which improves the ability of the supported player in the semi-final. For the latter interpretation, note that the valuations in all-pay-auctions can be interpreted as the 
abilities of the contestants (Baye et al., 1996). ${ }^{6}$

The support of $\mathrm{m}$ given to $\mathrm{h}$ is denoted by $\mathrm{e}_{\mathrm{mh}} \geq 0$, the support of $\mathrm{n}$ to $\mathrm{h}$ by $\mathrm{e}_{\mathrm{nh}} \geq 0$ and so on. Thus, player h's and player $\ell$ 's valuation of winning the semi-final can be written as

$$
\begin{aligned}
& \Pi_{\mathrm{h} 1}=\mathrm{p}_{\mathrm{n} 1} \Pi_{2}(\mathrm{~h}, \mathrm{n})+\left(1-\mathrm{p}_{\mathrm{n} 1}\right) \Pi_{2}(\mathrm{~h}, \mathrm{~m})+\mathrm{e}_{\mathrm{mh}}+\mathrm{e}_{\mathrm{nh}}, \\
& \Pi_{\ell 1}=\mathrm{p}_{\mathrm{n} 1} \Pi_{2}(\ell, \mathrm{n})+\left(1-\mathrm{p}_{\mathrm{n} 1}\right) \Pi_{2}(\ell, \mathrm{m})+\mathrm{e}_{\mathrm{m} \ell}+\mathrm{e}_{\mathrm{n} \ell},
\end{aligned}
$$

where $p_{n 1}$ is the probability that $n$ wins her semi-final against $m^{7}$ The first two terms in (2) represent player h's expected payoff if she advances to the final and meets either $m$ or $\mathrm{n}$. The last two terms in (2) equal the support player $\mathrm{h}$ receives from $\mathrm{m}$ and $\mathrm{n}$. If there were no help, a player's valuation will be equal to the first two terms in the above expressions. A similar interpretation holds for (3). The valuations of $m$ and $n$ in the other semi-final are

$$
\begin{aligned}
& \Pi_{\mathrm{m} 1}=\mathrm{p}_{\ell 1} \Pi_{2}(\mathrm{~m}, \ell)+\left(1-\mathrm{p}_{\ell 1}\right) \Pi_{2}(\mathrm{~m}, \mathrm{~h})+\mathrm{e}_{\mathrm{hm}}+\mathrm{e}_{\ell \mathrm{m}}, \\
& \Pi_{\mathrm{n} 1}=\mathrm{p}_{\ell 1} \Pi_{2}(\mathrm{n}, \ell)+\left(1-\mathrm{p}_{\ell 1}\right) \Pi_{2}(\mathrm{n}, \mathrm{h})+\mathrm{e}_{\mathrm{hn}}+\mathrm{e}_{\ell \mathrm{n}},
\end{aligned}
$$

where $\mathrm{p}_{\ell 1}$ is the probability that $\ell$ wins her semi-final against $\mathrm{h}$. The equilibria in the semi-finals are again in mixed-strategies. The equilibrium in each group is unique and can be characterized in the same way as the equilibrium in stage 2: The expected payoffs

\footnotetext{
${ }^{6}$ For the sake of analysis and to help focus on the role of sabotaging potential rivals, we do not consider sabotage of current rivals as in the single-state contests of Konrad (1999), Chen (2003), and Kräkel (2004). Moreover, note that in stage 2, the players' valuations revert to $V_{i}$ and $V_{j}$. That is, the effect of sabotage is not permanent.

${ }^{7}$ To give the reader an idea of how the help given to a player in a contest might increase her valuation, consider a contest where a player has a cost of effort e and valuation, $\mathrm{V}$. If the success probability is $\mathrm{P}$, we can write her payoff as PV - e. Suppose someone subsidies her cost of effort such that (1- $\alpha)$ of her cost is reimbursed, where $0<\alpha<1$. Then her payoff is now PV $-\alpha$ e. But this can re-written as $\alpha[\mathrm{PV} / \alpha-\mathrm{e}]$. Given that $\alpha$ is constant, this is equivalent to the original contest with no subsidy but with a player whose valuation has increased from $\mathrm{V}$ to $\mathrm{V} / \alpha$. Hence, we capture the help given to a player as an increase in her valuation.
} 
are analogous to (1) except for replacing the V's by the $\Pi$ 's defined in (2) - (5). And also the equilibrium total effort and the equilibrium winning probabilities, $\mathrm{p}_{\mathrm{n} 1}$ and $\mathrm{p}_{\ell 1}$, can be computed with the help of (2) - (5). In doing so, it is important to note that the valuations (2) - (5) themselves depend on $\mathrm{p}_{\mathrm{n} 1}$ and $\mathrm{p}_{\ell 1}$. Hence, when we solve the model in the next section, we have to compute $\mathrm{p}_{\mathrm{n} 1}$ and $\mathrm{p}_{\ell 1}$ by determining a fixed point (see also Groh et al., 2003).

Finally, we turn to stage 0 where the players determine their sabotage effort. The overall-payoffs of the players in stage 0 can be written as

$$
\begin{aligned}
& \Pi_{\mathrm{h} 0}=\max \left\{\Pi_{\mathrm{h} 1}-\Pi_{\ell 1}, 0\right\}-\mathrm{e}_{\mathrm{hm}}-\mathrm{e}_{\mathrm{hn}}, \\
& \Pi_{\ell 0}=\max \left\{\Pi_{\ell 1}-\Pi_{\mathrm{h} 1}, 0\right\}-\mathrm{e}_{\ell \mathrm{m}}-\mathrm{e}_{\ell \mathrm{n}}, \\
& \Pi_{\mathrm{m} 0}=\max \left\{\Pi_{\mathrm{m} 1}-\Pi_{\mathrm{n} 1}, 0\right\}-\mathrm{e}_{\mathrm{mh}}-\mathrm{e}_{\mathrm{m} \ell}, \\
& \Pi_{\mathrm{n} 0}=\max \left\{\Pi_{\mathrm{n} 1}-\Pi_{\mathrm{m} 1}, 0\right\}-\mathrm{e}_{\mathrm{nh}}-\mathrm{e}_{\mathrm{n} \ell} .
\end{aligned}
$$

The players' payoff in (6) - (9) equals the expected payoff the players receive from the semi-final (the maximum terms) less the sabotage efforts. In stage 0 , we look for a purestrategy equilibrium in the sabotage effort levels.

\section{Equilibrium under Different Seedings of Players}

There are different partitions of players in the semi-finals. These partitions are called seedings. Obviously, the properties of the equilibrium in our three-stage contest game depend on the seeding in the semi-finals. In what follows, we will therefore characterize the equilibrium for different seedings. 


\subsection{Seeding A: $\{1-3\}$ and $\{2-4\}$}

Suppose first that, in stage 1, players 1 and 3 belong to one group and players 2 and 4 belong to the other group (we call this grouping of players seeding A). In the notation of the previous section, we have $\mathrm{h}=1, \ell=3, \mathrm{~m}=2$ and $\mathrm{n}=4$. Obviously, player 4 will not engage in sabotage, i.e. $\mathrm{e}_{41}=\mathrm{e}_{43}=0$ is her dominant strategy, because according to $V_{1}>V_{2}>V_{3}>V_{4}>0$ and (1) her expected payoff from the contest in stage 2 is $k$ regardless of who she meets in that stage. Moreover, players 1 and 3 will benefit, if at all, only from sabotaging player 2 and player 2 only from sabotaging player 1 . This implies $\mathrm{e}_{12}=\mathrm{e}_{32}=\mathrm{e}_{21}=0$.

Given these insights and taking into account the equilibrium expected payoffs (1) in the final, we may specify the players' semi-final valuations (2) - (5) as

$$
\begin{aligned}
& \Pi_{11}=\mathrm{p}_{41}\left(\mathrm{~V}_{1}-\mathrm{V}_{4}+\mathrm{k}\right)+\left(1-\mathrm{p}_{41}\right)\left(\mathrm{V}_{1}-\mathrm{V}_{2}+\mathrm{k}\right)=\mathrm{V}_{1}-\mathrm{V}_{2}+\mathrm{p}_{41}\left(\mathrm{~V}_{2}-\mathrm{V}_{4}\right)+\mathrm{k}, \\
& \Pi_{31}=\mathrm{p}_{41}\left(\mathrm{~V}_{3}-\mathrm{V}_{4}+\mathrm{k}\right)+\left(1-\mathrm{p}_{41}\right) \mathrm{k}+\mathrm{e}_{23}=\mathrm{p}_{41}\left(\mathrm{~V}_{3}-\mathrm{V}_{4}\right)+\mathrm{k}+\mathrm{e}_{23}, \\
& \Pi_{21}=\mathrm{p}_{31}\left(\mathrm{~V}_{2}-\mathrm{V}_{3}+\mathrm{k}\right)+\left(1-\mathrm{p}_{31}\right) \mathrm{k}=\mathrm{p}_{31}\left(\mathrm{~V}_{2}-\mathrm{V}_{3}\right)+\mathrm{k}, \\
& \Pi_{41}=\left(1-\mathrm{p}_{31}\right) \mathrm{k}+\mathrm{p}_{31} \mathrm{k}+\mathrm{e}_{14}+\mathrm{e}_{34}=\mathrm{k}+\mathrm{e}_{14}+\mathrm{e}_{34} .
\end{aligned}
$$

In stage 2, player 2's net payoff if she meets player 3 instead of player 1 is $V_{2}-V_{3}$. This is an upper bound for her support of player 3, i.e., $e_{23} \leq V_{2}-V_{3}$. In the semi-final between players 1 and 3, we then obtain from (10) and (11)

$$
\Pi_{11}-\Pi_{31}=\mathrm{V}_{1}-\mathrm{V}_{2}+\mathrm{p}_{41}\left(\mathrm{~V}_{2}-\mathrm{V}_{3}\right)-\mathrm{e}_{23} \geq \mathrm{V}_{1}-\mathrm{V}_{2}+\left(\mathrm{p}_{41}-1\right)\left(\mathrm{V}_{2}-\mathrm{V}_{3}\right),
$$

given $e_{23} \leq V_{2}-V_{3}$. Thus, no matter the relative size of the valuations $\Pi_{41}$ and $\Pi_{21}$, player 1 has a higher valuation than player 3 in stage 1 (i.e., $\Pi_{11}>\Pi_{31}$ ), if 
$\mathrm{V}_{1}-\mathrm{V}_{2} \geq \mathrm{V}_{2}-\mathrm{V}_{3}$. It follows that when they contest in an all-pay auction in stage 1 ,

player 1 will get a positive expected payoff, but player 3 will get a zero expected payoff.

Hence, $V_{1}-V_{2} \geq V_{2}-V_{3}$ implies that in stage 0 player 3 will not invest in sabotage.

Therefore, in a reduced-form game obtained via backward induction, $\mathrm{e}_{34}=0$ is a

dominant strategy for player 3 in stage 0 .

It remains to specify the sabotage effort levels of player 1 and $2, \mathrm{e}_{14}$ and $\mathrm{e}_{23}$.

Since $V_{1}-V_{2} \geq V_{2}-V_{3}$ implies $\Pi_{11}>\Pi_{31}$, only two cases have to be distinguished: In

case 1, we have $\Pi_{11}>\Pi_{31}$ and $\Pi_{21} \leq \Pi_{41}$. According to (6) - (9) and the dominant

strategies derived so far, the players' payoffs in stage 0 are

$$
\begin{aligned}
& \Pi_{10}=\Pi_{11}-\Pi_{31}-\mathrm{e}_{14}=\mathrm{V}_{1}-\mathrm{V}_{2}+\mathrm{p}_{41}\left(\mathrm{~V}_{2}-\mathrm{V}_{3}\right)-\mathrm{e}_{14}, \quad \Pi_{30}=0, \\
& \Pi_{40}=\Pi_{41}-\Pi_{21}=\mathrm{e}_{14}-\mathrm{p}_{31}\left(\mathrm{~V}_{2}-\mathrm{V}_{3}\right), \quad \Pi_{20}=-\mathrm{e}_{23} .
\end{aligned}
$$

In case 2 , we have $\Pi_{11}>\Pi_{31}$ and $\Pi_{21} \geq \Pi_{41}$, and the players' payoffs in stage 0 become

$$
\begin{aligned}
& \Pi_{10}=\Pi_{11}-\Pi_{31}-\mathrm{e}_{14}=\mathrm{V}_{1}-\mathrm{V}_{2}+\mathrm{p}_{41}\left(\mathrm{~V}_{2}-\mathrm{V}_{3}\right)-\mathrm{e}_{23}-\mathrm{e}_{14}, \quad \Pi_{30}=0, \\
& \Pi_{20}=\Pi_{21}-\Pi_{41}-\mathrm{e}_{23}=\mathrm{p}_{31}\left(\mathrm{~V}_{2}-\mathrm{V}_{3}\right)-\mathrm{e}_{14}-\mathrm{e}_{23}, \quad \Pi_{40}=0 .
\end{aligned}
$$

Players 1 and 2 will set their sabotage effort levels such that their payoff in stage 0 is maximized. In doing so, each of them takes into account the effect of her sabotage effort on the winning probabilities in stage $1, \mathrm{p}_{41}$ and $\mathrm{p}_{31}$. We look for a pure-strategy equilibrium. For notational convenience, let $a:=V_{1}-V_{2}, b:=V_{2}-V_{3}$ and $c:=V_{3}-V_{4}$. We then obtain 
Proposition 1: Suppose the players' valuations are such that $\mathrm{V}_{1}>\mathrm{V}_{2}>\mathrm{V}_{3}>\mathrm{V}_{4}$ and $\mathrm{V}_{1}-\mathrm{V}_{2} \geq \mathrm{V}_{2}-\mathrm{V}_{3}$, players 1 and 3 belong to one group and players 2 and 4 belong to another group and $\mathrm{k} \rightarrow 0$. Then there exists a pure-strategy subgame perfect equilibrium in which only the most able player (i.e., player 1) engages in sabotage. Her equilibrium sabotage effort $\mathrm{e}_{14}^{*}>0$ is determined by

$$
b^{2} c \frac{\sqrt{\left[4(a-b-c) e_{14}^{*}+b c\right]^{2}+64 a(b+c) e_{14}^{* 2}}-4(a-b-c) e_{14}^{*}-b c}{8(b+c) e_{14}^{* 2} \sqrt{\left[4(a-b-c) e_{14}^{*}+b c\right]^{2}+64 a(b+c) e_{14}^{* 2}}}=1 .
$$

The equilibrium is such that, $\Pi_{21}<\Pi_{41}, \Pi_{11}>\Pi_{31}, \mathrm{p}_{41}>1 / 2, \mathrm{p}_{31}<1 / 2, \Pi_{10}>0$, $\Pi_{40}>0$ and $\Pi_{20}=\Pi_{30}=0$.

Proof: We first look for a possible equilibrium in case 1, i.e. $\Pi_{11}>\Pi_{31}$ and $\Pi_{21} \leq \Pi_{41}$. The players' stage 0 payoffs in this case are captured by (15) and (16). $\Pi_{20}=-\mathrm{e}_{23}$ immediately implies that $\mathrm{e}_{23}=0$ is a dominant strategy for player 2 in this subgame. In order to obtain player 1's optimal sabotage effort, we first have to determine the equilibrium winning probabilities in stage $1, \mathrm{p}_{31}$ and $\mathrm{p}_{41}$, as functions of the sabotage effort chosen in stage 0 . These functions are determined by using a result of Baye et al. (1996). Given $\Pi_{11}>\Pi_{31}$ and $\Pi_{21} \leq \Pi_{41}$, we obtain

$$
\mathrm{p}_{31}=\frac{\Pi_{31}}{2 \Pi_{11}}=\frac{\mathrm{cp}_{41}+\mathrm{k}}{2 \mathrm{a}+2(\mathrm{~b}+\mathrm{c}) \mathrm{p}_{41}+2 \mathrm{k}}, \quad \mathrm{p}_{41}=1-\frac{\Pi_{21}}{2 \Pi_{41}}=1-\frac{\mathrm{bp}_{31}+\mathrm{k}}{2 \mathrm{e}_{14}+2 \mathrm{k}}
$$


The fixed point of these equations with respect to $\mathrm{p}_{31}$ and $\mathrm{p}_{41}$ yields the desired functions. It is obtained by simultaneously solving the two equations above. For our purposes, we only need the solution for $\mathrm{p}_{41}$. Letting $\mathrm{k} \rightarrow 0$ gives

$$
p_{41}=\frac{4(b+c-a) e_{14}-b c+\sqrt{\left[4(a-b-c) e_{14}+b c\right]^{2}+64 a(b+c) e_{14}^{2}}}{8(b+c) e_{14}}
$$

Player 1 sets $e_{14}$ such that $\Pi_{10}$ from (15) is maximized. Taking into account the derivative of (20) with respect to $\mathrm{e}_{14}$ yields

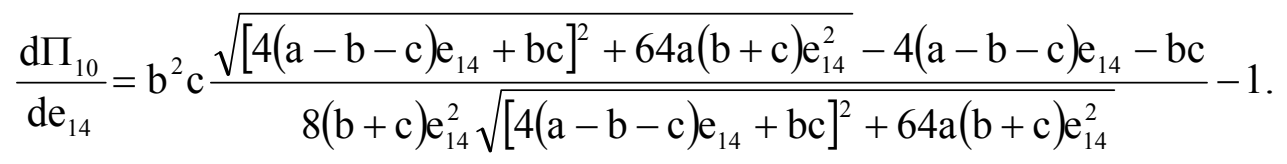

The lowest sabotage effort which player 1 can choose in case 1 is the one which equates $\Pi_{21}$ and $\Pi_{41}$ or, equivalently, which reduces the winning probability of player 4 to $\mathrm{p}_{41}=1 / 2$. From (20) we obtain $\mathrm{p}_{41}=1 / 2$ iff $\mathrm{e}_{14}=\mathrm{bc} /(4 \mathrm{a}+2 \mathrm{~b}+2 \mathrm{c})=: \mathrm{e}_{14}^{\min }$. If we evaluate player 1's marginal payoff (21) at $\mathrm{e}_{14}=\mathrm{e}_{14}^{\min }$, we obtain

$$
\left.\frac{\mathrm{d} \Pi_{10}}{\mathrm{de}_{14}}\right|_{\mathrm{e}_{14}=\mathrm{e}_{14}^{\min }}=\frac{(2 \mathrm{a}+\mathrm{b})^{2}+\mathrm{bc}}{\mathrm{c}(4 \mathrm{a}+\mathrm{b}+\mathrm{c})}>0
$$

This implies that, in case 1 , player 1 always chooses an interior solution $\mathrm{e}_{14}>\mathrm{e}_{14}^{\mathrm{min}}>0$. This is the solution to $\mathrm{d} \Pi_{10} / \mathrm{de}_{14}=0$ in (21) above or, equivalently, to (19). We assume that a feasible solution exists. Indeed, we present an example in corollary 1 . We can therefore conjecture that a possible candidate for a pure-strategy equilibrium is one in which players 2,3 , and 4 do not invest in sabotage, but player 1 chooses $\mathrm{e}_{14}^{*}>\mathrm{e}_{14}^{\min }>0$ where $\mathrm{e}_{14}^{*}$ is implicitly defined by (19). In this possible equilibrium, we have $\Pi_{21}<\Pi_{41}$, $\Pi_{11}>\Pi_{31}, \mathrm{p}_{41}>1 / 2$ and $\mathrm{p}_{31}<1 / 2$. To ensure that the candidate equilibrium is indeed 
an equilibrium, we have to make sure that the players do not have an incentive to deviate from their choice when we turn to case 2 .

In case 2 , we have $\Pi_{11}>\Pi_{31}$ and $\Pi_{21} \geq \Pi_{41}$. The stage 0 payoffs are captured by (17) and (18). The winning probabilities in stage $1, \mathrm{p}_{31}$ and $\mathrm{p}_{41}$, are now functions of the sabotage efforts $\mathrm{e}_{14}$ and $\mathrm{e}_{23}$. Using results of Baye et al. (1996) yield

$$
\mathrm{p}_{31}=\frac{\Pi_{31}}{2 \Pi_{11}}=\frac{\mathrm{cp}_{41}+\mathrm{e}_{23}+\mathrm{k}}{2 \mathrm{a}+2(\mathrm{~b}+\mathrm{c}) \mathrm{p}_{41}+2 \mathrm{k}}, \quad \mathrm{p}_{41}=\frac{\Pi_{41}}{2 \Pi_{21}}=\frac{\mathrm{e}_{14}+\mathrm{k}}{2 \mathrm{bp} \mathrm{p}_{31}+2 \mathrm{k}}
$$

Solving these equations with respect to $\mathrm{p}_{31}$ and $\mathrm{p}_{41}$ and letting $\mathrm{k} \rightarrow 0$ gives

$$
\begin{aligned}
& \mathrm{p}_{31}=\frac{\mathrm{be}_{23}-(\mathrm{b}+\mathrm{c}) \mathrm{e}_{14}+\sqrt{\left[\mathrm{be}_{23}-(\mathrm{b}+\mathrm{c}) \mathrm{e}_{14}\right]^{2}+4 a b c e_{14}}}{4 \mathrm{ab}} \\
& \mathrm{p}_{41}=\frac{(\mathrm{b}+\mathrm{c}) \mathrm{e}_{14}-\mathrm{be}_{23}+\sqrt{\left[\mathrm{be}_{23}-(\mathrm{b}+\mathrm{c}) \mathrm{e}_{14}\right]^{2}+4 a b c e_{14}}}{2 \mathrm{bc}} .
\end{aligned}
$$

Consider first player 2. She chooses $\mathrm{e}_{23}$ such that $\Pi_{20}$ from (18) is maximized. Taking into account the derivative of (23) with respect to $\mathrm{e}_{23}$ yields

$$
\frac{d \Pi_{20}}{\mathrm{de}_{23}}=\frac{\mathrm{b}}{4 \mathrm{a}} \frac{\sqrt{\left[\mathrm{be}_{23}-(\mathrm{b}+\mathrm{c}) \mathrm{e}_{14}\right]^{2}+4 a b c e_{14}}+\mathrm{be}_{23}-(\mathrm{b}+\mathrm{c}) \mathrm{e}_{14}}{\sqrt{\left[\mathrm{be}_{23}-(\mathrm{b}+\mathrm{c}) \mathrm{e}_{14}\right]^{2}+4 a b c e_{14}}}-1
$$

Since we assume $V_{1}-V_{2} \geq V_{2}-V_{3}$ or $a \geq b$, it is straightforward to show that $\mathrm{d} \Pi_{20} / \mathrm{de}_{23}<0$ for all $\mathrm{e}_{23}, \mathrm{e}_{14} \geq 0$. Hence, player 2 has the dominant strategy $\mathrm{e}_{23}=0$ in this subgame and has no incentive to deviate from the candidate equilibrium we determined in case 1 .

Next turn to player 1 . She sets $e_{14}$ such that $\Pi_{10}$ from (17) is maximized. Taking into account the derivatives of (24) with respect to $\mathrm{e}_{14}$ yields 


$$
\begin{aligned}
& \frac{d \Pi_{10}}{\mathrm{de}_{14}}=\frac{(b+c) \sqrt{(b+c)^{2} e_{14}^{2}+4 a b c e_{14}}+(b+c)^{2} e_{14}+2 a b c}{2 c \sqrt{(b+c)^{2} e_{14}^{2}+4 a b c e_{14}}}-1, \\
& \frac{d^{2} \Pi_{10}}{{d e_{14}^{2}}^{2}}=-\frac{2 a^{2} b^{2} c}{\left[(b+c)^{2} e_{14}^{2}+4 a b c e_{14}\right]^{3 / 2}}<0 .
\end{aligned}
$$

If $\mathrm{e}_{14} \rightarrow 0$, then the numerator in $(25)$ tends to $2 \mathrm{abc}>0$ while the denominator tends to 0 . Hence, $\mathrm{e}_{14} \rightarrow 0$ implies $\mathrm{d} \Pi_{10} / \mathrm{de}_{14} \rightarrow \infty$. If $\mathrm{e}_{14} \rightarrow \infty$, then L'Hôpital's rule yields $\mathrm{d} \Pi_{10} / \mathrm{de}_{14} \rightarrow \mathrm{b} / \mathrm{c}>0$ Equation (26) then implies $\mathrm{d} \Pi_{10} / \mathrm{de}_{14}>0$ for all $\mathrm{e}_{14} \geq 0$. Hence, player 1 chooses $\mathrm{e}_{14}$ as large as possible. Since it is straightforward to show that an increase in $\mathrm{e}_{14}$ increases $\Pi_{11}-\Pi_{31}$ and decreases $\Pi_{21}-\Pi_{41}$, player 1 sets $\mathrm{e}_{14}$ such that $\Pi_{21}=\Pi_{41}$ or, equivalently, $\mathrm{p}_{41}=1 / 2$. Using (24) and $\mathrm{e}_{23}=0$, we again obtain $\mathrm{p}_{41}=1 / 2$ iff $\mathrm{e}_{14}=\mathrm{e}_{14}^{\mathrm{min}}$. But we know from our analysis of case 1 , that player 1 obtains a higher payoff if she chooses $\mathrm{e}_{14}=\mathrm{e}_{14}^{*}>\mathrm{e}_{14}^{\mathrm{min}}$. Hence, player 1 also has no incentive to deviate from the candidate equilibrium in case 1 . Therefore, this candidate equilibrium is indeed a pure-strategy equilibrium. This completes the proof of proposition 1. QED.

Proposition 1 states that under seeding A, there exists a pure-strategy equilibrium in which the most able contestant invests in sabotage, but all other (less able) contestants do not. The intuition is straightforward: Player 1 prefers to play the final against the weakest player (i.e. player 4) instead of the second-best player (i.e. player 2). Hence, player 1 supports player 4 such that this player has a higher chance of winning her semifinal than player 2 , even though player 2 is more able in the sense that she has a larger valuation of winning the final. This indirect sabotage of player 2 by player 1 implies that 
player 1's and 4's expected payoff in stage 0 is strictly positive, while players 2 and 3 have zero expected payoff in stage 0 . We will further discuss the rational of this result in section 4, when we compare our results with those of previous works.

Equation (19) can explicitly be solved for the equilibrium sabotage effort of player 1. This would yield some insights about the impact which the model parameters have on the magnitude of the sabotage effort. But in the general case, it does not provide useful analytical results. To highlight some properties of the sabotage equilibrium, we therefore focus on the special case where the differences between the valuations are equal, i.e. $\mathrm{V}_{1}-\mathrm{V}_{2}=\mathrm{V}_{2}-\mathrm{V}_{3}=\mathrm{V}_{3}-\mathrm{V}_{4}=: \mathrm{x}>0$ or, equivalently, $\mathrm{a}=\mathrm{b}=\mathrm{c}=: \mathrm{x}>0$. Equation (19) then has three and only three solutions with respect to player 1's sabotage effort: $\mathrm{e}_{14}=\mathrm{x} / 4$ and $\mathrm{e}_{14}=\mathrm{x}(-8 \pm \sqrt{10}) / 36$. But only the first solution is positive and only for this solution is the second-order condition for a local maximum satisfied. Using equations (15) and (20), player 1's payoff at $\mathrm{e}_{14}=\mathrm{x} / 4$ can be shown to equal $\Pi_{10}=\mathrm{x}(3+\sqrt{8}) / 4>\mathrm{x}>0$. To show that this is a global maximum, we evaluate player 1 's payoff at the extreme ends of the domain of $e_{14}$ (i.e., at 0 and $V_{2}-V_{4}=2 x$ ). Using (15) and (20), player 1's payoff at $\mathrm{e}_{14}=0$ is equal to $\mathrm{x}$, since the limiting value of $\mathrm{p}_{41}=0$ given $\mathrm{e}_{14}=0$. Using (15), player 1's payoff is $\mathrm{x}\left(\mathrm{p}_{41}-1\right)<0$ at $\mathrm{e}_{14}=2 \mathrm{x}$. Therefore, the payoffs at the extreme ends of the domain of $\mathrm{e}_{14}$ are less than $\Pi_{10}=\mathrm{x}(3+\sqrt{8}) / 4>\mathrm{x}$, and the global maximum of player 1's payoff is at $\mathrm{e}_{14}=\mathrm{x} / 4$. Since, players 2,3 , and 4 have strictly dominant strategies, we have a unique pure-strategy equilibrium with player 1's sabotage effort $\mathrm{e}_{14}^{*}=\mathrm{x} / 4 .{ }^{8}$ Using (10) $-(13),(15),(16)$ and (20) it is straightforward to

\footnotetext{
${ }^{8}$ Note that $\mathrm{e}_{14}^{*}=\mathrm{x} / 4=\mathrm{c} / 4<\mathrm{V}_{2}-\mathrm{V}_{4}$.
} 
compute the accompanying equilibrium winning probabilities, valuations in stage 1 and payoffs in stage 0 . Overall, we obtain

Corollary 1: Under the same conditions as in proposition 1 and additionally $V_{1}-V_{2}=$ $V_{2}-V_{3}=V_{3}-V_{4}=: x>0$, there exists a unique pure-strategy subgame perfect equilibrium in which only the most able player (i.e., player 1) chooses a positive sabotage effort $\mathrm{e}_{14}^{*}=\mathrm{x} / 4$. In this equilibrium, we have $\Pi_{21}=\mathrm{x}(2-\sqrt{2}) / 4<\mathrm{x} / 4=\Pi_{41}$,

$$
\begin{aligned}
& \Pi_{11}=\mathrm{x}(1+\sqrt{2})>\mathrm{x} \sqrt{2} / 2=\Pi_{31}, \mathrm{p}_{41}=1 / \sqrt{2}>1 / 2, \mathrm{p}_{31}=(2-\sqrt{2}) / 4<1 / 2, \\
& \Pi_{10}=\mathrm{x}(3+\sqrt{8}) / 4>0, \Pi_{40}=\mathrm{x}(\sqrt{2}-1) / 4>0 \text { and } \Pi_{20}=\Pi_{30}=0 .
\end{aligned}
$$

Corollary 1 states that in the special case of equal differences between the players' valuations, the sabotage equilibrium derived in proposition 1 is unique. Moreover, player 1 's sabotage effort as well as the stage 0 expected payoffs of players 1 and 4 are increasing in $\mathrm{x}$. The rationale of this insight is as follows: The larger the (common) difference between the valuations of the players, the larger is player 1's benefit from playing a final against player 4 instead of player 2 . Hence, an increase in x makes sabotage more profitable for player 1 such that player 1 chooses a higher sabotage effort and the payoffs of players 1 and 4 increase.

With the semi-final valuations listed in corollary 1 , we are also able to compute the productive effort levels in the final and the semi-finals. Let $\mathrm{E}_{\mathrm{ij}}^{\mathrm{S}}$ be total expected productive effort in a semi-final between players $i$ and $j$ when there is sabotage and let $\widetilde{\mathrm{E}}_{\mathrm{ij}}^{\mathrm{s}}$ be total expected productive effort in the semi-final between $\mathrm{i}$ and $\mathrm{j}$ when there is no 
sabotage. Similarly, $\mathrm{E}^{\mathrm{F}}$ and $\widetilde{\mathrm{E}}^{\mathrm{F}}$ denote total expected productive effort in the final when there is sabotage and when there is no sabotage, respectively. In appendix A, we prove ${ }^{9}$

Proposition 2: Under the same conditions as in corollary 1, we have $\mathrm{E}_{13}^{\mathrm{S}}>\widetilde{\mathrm{E}}_{13}^{\mathrm{S}}=0$, $\mathrm{E}_{24}^{\mathrm{S}}>\widetilde{\mathrm{E}}_{24}^{\mathrm{S}}=0, \mathrm{E}^{\mathrm{F}}<\widetilde{\mathrm{E}}^{\mathrm{F}}$ and $\mathrm{E}_{13}^{\mathrm{S}}+\mathrm{E}_{24}^{\mathrm{S}}+\mathrm{E}^{\mathrm{F}}<\widetilde{\mathrm{E}}_{13}^{\mathrm{S}}+\widetilde{\mathrm{E}}_{24}^{\mathrm{S}}+\widetilde{\mathrm{E}}^{\mathrm{F}}$.

The intuition for these results is as follows: In the semi-final of the sabotage equilibrium, player 1 supports player 4 . Hence, player 4 is stronger than in the no-sabotage equilibrium so that player 2 has to exert a larger productive effort resulting in an increase in the aggregate expected effort levels in the semi-final between 2 and 4 compared to the case without sabotage $\left(\mathrm{E}_{24}^{\mathrm{S}}>\widetilde{\mathrm{E}}_{24}^{\mathrm{S}}=0\right.$ ). Moreover, advancing to the final becomes more attractive to the participants of the other semi-final, players 1 and 3, since player 4 has a higher chance of winning her semi-final. Hence, players 1 and 3 choose higher productive effort levels than in the no-sabotage equilibrium $\left(\mathrm{E}_{13}^{\mathrm{S}}>\widetilde{\mathrm{E}}_{13}^{\mathrm{S}}=0\right)$. In sum, sabotage is good for the productive effort levels in the semi-finals. However, the expected effort level in the final is reduced by sabotage $\left(\mathrm{E}^{\mathrm{F}}<\widetilde{\mathrm{E}}^{\mathrm{F}}\right)$. The reason is that the final is now not necessarily between the strongest players (in the case without sabotage, the final takes place between players 1 and 2 with almost sure certainty, see Groh et al., 2003). Sabotage is therefore bad for productive effort in the final. And this negative effect of sabotage on productive effort in the final outweighs the positive effect of

\footnotetext{
${ }^{9}$ The first two results in proposition 2 are true also for the general case where $\mathrm{a}, \mathrm{b}$ and/or $\mathrm{c}$ may be different from $\mathrm{x}$. But for the rest of the results in proposition 2, we need the condition $\mathrm{a}=\mathrm{b}=\mathrm{c}=\mathrm{x}$.
} 
sabotage on productive effort in the semi-finals so that total productive effort from both stages is reduced by sabotage.

\subsection{Seeding $B:\{1-2\}$ and $\{3-4\}$}

Now suppose the two strongest players are grouped in one semi-final and the two weakest players in the other semi-final (we call this grouping seeding B). In the notation of section 2 , we may write $\mathrm{h}=2, \ell=1, \mathrm{~m}=4$ and $\mathrm{n}=3$. If at all, players 1 and 2 will benefit only from indirectly sabotaging player 3 and players 3 and 4 only from sabotaging player 1 . Hence, we can already identify $\mathrm{e}_{13}=\mathrm{e}_{23}=\mathrm{e}_{31}=\mathrm{e}_{41}=0$ as dominant strategies.

Given this insight and computing the equilibrium expected payoffs (1) in the final, we may now specify the players' semi-final valuations (2) - (5) as

$$
\begin{aligned}
& \Pi_{11}=\mathrm{p}_{31}\left(\mathrm{~V}_{1}-\mathrm{V}_{3}+\mathrm{k}\right)+\left(1-\mathrm{p}_{31}\right)\left(\mathrm{V}_{1}-\mathrm{V}_{4}+\mathrm{k}\right)=\mathrm{V}_{1}-\mathrm{V}_{4}-\mathrm{p}_{31}\left(\mathrm{~V}_{3}-\mathrm{V}_{4}\right)+\mathrm{k} \\
& \begin{aligned}
\Pi_{21} & =\mathrm{p}_{31}\left(\mathrm{~V}_{2}-\mathrm{V}_{3}+\mathrm{k}\right)+\left(1-\mathrm{p}_{31}\right)\left(\mathrm{V}_{2}-\mathrm{V}_{4}+\mathrm{k}\right)+\mathrm{e}_{32}+\mathrm{e}_{42} \\
& =\mathrm{V}_{2}-\mathrm{V}_{4}-\mathrm{p}_{31}\left(\mathrm{~V}_{3}-\mathrm{V}_{4}\right)+\mathrm{k}+\mathrm{e}_{32}+\mathrm{e}_{42}
\end{aligned} \\
& \Pi_{31}=\mathrm{p}_{11} \mathrm{k}+\left(1-\mathrm{p}_{11}\right) \mathrm{k}=\mathrm{k} \\
& \Pi_{41}=\mathrm{p}_{11} \mathrm{k}+\left(1-\mathrm{p}_{11}\right) \mathrm{k}+\mathrm{e}_{14}+\mathrm{e}_{24}=\mathrm{k}+\mathrm{e}_{14}+\mathrm{e}_{24}
\end{aligned}
$$

where $p_{31}$ is the probability that player 3 advances to the final and $p_{11}$ is the probability that player 1 advances to the final.

To determine the equilibrium on stage 0 of the game, note first that (29) and (30) imply $\Pi_{41}-\Pi_{31}=\mathrm{e}_{14}+\mathrm{e}_{24} \geq 0$. Hence, the payoffs of players 3 and 4 on stage 0 are $\Pi_{30}=-\mathrm{e}_{32}$ and $\Pi_{40}=\Pi_{41}-\Pi_{31}-\mathrm{e}_{42}=\mathrm{e}_{14}+\mathrm{e}_{24}-\mathrm{e}_{42}$, respectively. These payoffs immediately imply $\mathrm{e}_{32}=\mathrm{e}_{42}=0$, i.e., players 3 and 4 do not invest in sabotage. A similar 
argument holds for the semi-final between players 1 and 2. From (27), (28) and $\mathrm{e}_{32}=\mathrm{e}_{42}=0$ we obtain $\Pi_{11}-\Pi_{21}=\mathrm{V}_{1}-\mathrm{V}_{2}>0$. This implies $\Pi_{20}=-\mathrm{e}_{24}$ and $\Pi_{10}=\Pi_{11}-\Pi_{21}-\mathrm{e}_{14}=\mathrm{V}_{1}-\mathrm{V}_{2}-\mathrm{e}_{14}$. It follows that $\mathrm{e}_{14}=\mathrm{e}_{24}=0$, i.e., players 1 and 2 also do not have an incentive for sabotage. We summarize this finding in

Proposition 3: Suppose the players' valuations are such that $\mathrm{V}_{1}>\mathrm{V}_{2}>\mathrm{V}_{3}>\mathrm{V}_{4}$ and players 1 and 2 belong to one group and players 3 and 4 belong to another group. Then there exists a unique pure-strategy subgame perfect equilibrium in which no player engages in sabotage.

Players 3 and 4 have a smaller valuation of the final than players 1 and 2. Hence, both know that, even if they win the semi-final, the payoff in the final will be $\mathrm{k}$, independent of whether they play the final against player 1 or player 2 . Hence, indirectly sabotaging player 1 does not pay for the two weakest players, so they choose a zero sabotage effort. Player 1 is stronger than player 2 in the semi-final among the two strongest players. Given the zero sabotage efforts of players 3 and 4, player 2's expected payoff from the semi-final is zero regardless of her sabotage effort. Hence, player 2 also chooses a zero sabotage effort. Finally, player 1's payoff from the semi-final against player 2 equals the difference between her valuation and that of player 2 , independent of the sabotage effort player 1 chooses. Hence, player 1 also decides to abstain from sabotage. In sum, under seeding B the possibility to sabotage potential rivals does not change the equilibrium in the final and the semi-final found in Groh et. al (2003). ${ }^{10}$

\footnotetext{
${ }^{10}$ Note also that proposition 3 is true not only in the limiting case $\mathrm{k} \rightarrow 0$, but for all values of $\mathrm{k}>0$.
} 


\subsection{Seeding $C:\{1,4\}$ and $\{2,3\}$}

Finally, we take a look at the case where the strongest and the weakest player are grouped in one semi-final and the two middle players are grouped in the other semi-final (we call this grouping seeding C). In the notation of section 2 , we may write $\mathrm{h}=1, \ell=4, \mathrm{~m}=2$ and $\mathrm{n}=3$. For this seeding, appendix B proves

Proposition 4: Suppose the players' valuations are such that $\mathrm{V}_{1}>\mathrm{V}_{2}>\mathrm{V}_{3}>\mathrm{V}_{4}$ and players 1 and 4 belong to one group and players 2 and 3 belong to another group and $\mathrm{k} \rightarrow 0$. Then

(i) there does not exist a pure-strategy subgame perfect equilibrium in which only the most able player invests in sabotage, and

(ii) there does not exist a pure-strategy subgame perfect equilibrium in which none of the players invest in sabotage.

The insight of this proposition is that in seeding $\mathrm{C}$ we cannot have pure-strategy equilibria as those derived in seedings A and B. The intuition of part (i) is that in seeding $\mathrm{C}$, player 2 has the highest benefit from sabotage (i.e., $\mathrm{V}_{2}-\mathrm{V}_{4}$ ). Hence, an equilibrium in which player 1 - who has a lower benefit from sabotage (i.e., $V_{2}-V_{3}$ ) - invests in sabotage but player 2 does not, is not possible. The rational of part (ii) is that, in contrast to seeding $\mathrm{B}$, in both semi-finals of seeding $\mathrm{C}$ at least one player would benefit from sabotage (remember that in the semi-final $\{3,4\}$ under seeding B none of the players 
benefits from sabotage and this is the driving force for the no-sabotage equilibrium in proposition 3).

Notice that also in seeding $\mathrm{C}$ player 4 does not engage in sabotage. For players 2 and 3, only one of them will engage in sabotage, because at least one of them will not have a bigger semi-final valuation than the other. Hence, proposition 4 implies that an equilibrium, if it exists, must have the property that at least one player (either 2 or 3 ) and at most two players ( 1 and 2 or 1 and 3 ) will engage in sabotage. If there exists an equilibrium in which only one player invests in sabotage, that player cannot be player 1, given proposition 4(i). But if player 1 does not invest in sabotage, then player 2 has a bigger semi-final valuation than player 3 . Therefore, if only one player engages in sabotage, then that player must be player 2. Unfortunately, due to the discontinuity of the winning probabilities and the payoff functions which lead to proposition 4 (see the proof in appendix B), it is difficult to analytically derive an equilibrium for seeding $\mathrm{C}$ in the case of $\mathrm{V}_{1}>\mathrm{V}_{2}>\mathrm{V}_{3}>\mathrm{V}_{4}$.

In appendix $C$, we show that in case of $V_{1}>V_{2}=V_{3}>V_{4}$, there is a purestrategy subgame perfect equilibrium under seeding $\mathrm{C}$ in which no player engages in sabotage. Indeed, if $V_{2}=V_{3}(b=0)$, then it is straightforward to show that there is no sabotage in any of the seedings. But this insight implies that $\mathrm{V}_{2}>\mathrm{V}_{3}$ is crucial to the sabotage equilibrium we derived in proposition 1 for seeding A. ${ }^{11}$

\footnotetext{
${ }^{11}$ Note that the probabilities in equations (23) and (24) are undefined if $b=0$ (i.e., $V_{2}=V_{3}$ ).
} 


\section{Discussion of Results}

In proposition 1 , the result that $\mathrm{p}_{41}>1 / 2$ is interesting. Player 4 has a higher winning probability than player 2 in the semi-final although player 2 has a higher ability. Chen (2003) also finds that a player with a higher ability might have a lower probability of success than a player with a lower ability because other contestants direct more sabotage effort at the player with a higher ability.

In what follows, all the results when sabotage is not feasible are taken from Groh et al. (2003). If sabotage is not feasible, player 1's success probability in seeding $\mathrm{A}^{12}$ is 1 as $\mathrm{k} \rightarrow 0$. Player 1 's probability of success in stage 1 is less than 1 , if sabotage is feasible. ${ }^{13}$ However, player 1 prefers the sabotage equilibrium because the probability of meeting player 4 is higher. ${ }^{14}$ Player 2 has a higher success probability if sabotage is not feasible. She prefers the no-sabotage equilibrium (i.e., when sabotage is not feasible) because her payoff is positive which is greater than her zero payoff in the sabotage equilibrium. Player 3 is indifferent because her payoff is zero in both equilibria but player 4 prefers the sabotage equilibrium. In sum, if the goal is to improve the selection properties of the contest, then allowing sabotage is bad because the top two players, 1 and 2 , have lower success probabilities in the sabotage equilibrium than in the no-sabotage equilibrium. However, the sabotage equilibrium may be preferred by some of the players including the most able player.

\footnotetext{
${ }^{12}$ Notice that we label the seedings differently from Groh et al. (2003).

${ }^{13}$ It is easy to show that $p_{31}>0$, which implies that $p_{11}<1$. The proof of this result is available on request. But corollary 1 gives an example.

${ }^{14}$ Notice that, in proposition 1 , player 1 could have chosen $\mathrm{e}_{14}=0$ in the sabotage equilibrium (given that the others players have chosen zero sabotage) but she did not. Clearly, she must be better off by choosing a positive level of sabotage.
} 
Indeed, a difference between our result and Chen (2003) is that the most able player may be better off when indirect sabotage is allowed. This result is not possible in Chen (2003), where only direct sabotage is allowed. Another difference is that in Chen (2003) it is never the case that a more able player engages in sabotage but a less able player does not. ${ }^{15}$ In our model, this is possible. In seeding A, it is not surprising that player 1 is the only one who engages in sabotage once we notice that she derives the highest benefit from sabotage. The benefits of a successful sabotage are $V_{2}-V_{4}, V_{2}-V_{3}$, $V_{3}-V_{4}$, and zero to players $1,2,3$, and 4 , respectively. It is easy to see that $V_{2}-V_{4}$ is the highest of these benefits.

It is insightful to examine the difference in results between seedings A and B. The main difference between proposition 1 (seeding A) and proposition 3 (seeding B) is that player 1 invests in sabotage in seeding A but not in seeding B. This result accords with intuition. In seeding A, player 1's benefit of successful sabotage is that she meets player 4 instead of player 2. In seeding B, player 1's benefit of successful sabotage is that she meets player 4 instead of player 3. Clearly, player 1's benefit of sabotage is higher under seeding A than under seeding B. This explains why player 1 invests in sabotage under seeding A, but never does in seeding B.

An alternative explanation for why player 1 does not invest in sabotage in seeding $\mathrm{B}$ is based on the observation that sabotage is a public good. Notice that the benefits of sabotage by a player are also enjoyed by the player in his group. In seeding B,

\footnotetext{
${ }^{15}$ In a model with two players where only the sabotage of current rivals is possible, Kräkel (2004) also finds an equilibrium in which only the more able player invests in sabotage. However, sabotage is costless is in his model. Also, he does not investigate sabotage of potential rivals, so the rationale of the result in his model is completely different from the one in our model. Finally, his model is unable to generate equilibria where no player invests in sabotage or a player with lower ability has a higher probability of success.
} 
if player 1 sabotages player 3 , that also benefits player 2. Given the public good nature of sabotage, a necessary condition for player 1 to invest in sabotage is that the benefits of sabotage must be bigger for player 1 than for player 2 such that the difference $\Pi_{11}-\Pi_{21}$ increases. But this difference is a constant, $\Pi_{11}-\Pi_{21}=V_{1}-V_{2}>0$ in seeding B. Conversely, in seeding A, the difference $\Pi_{11}-\Pi_{31}=V_{1}-V_{2}+p_{41}\left(V_{2}-V_{3}\right)$ is increasing in the success probability of player 4. Notice that player 1 gets a positive payoff no matter who she meets in the final. Player 3 only gets a positive payoff if she meets player 4 . The difference in the gains from this public good (i.e., sabotage) are not the same. It is not surprising then that player 1, the player with the higher valuation (gain) for this public good, provides the public good in seeding A.

It is important to note that sabotage and productive effort are not perfect substitutes although they both have the same constant marginal costs. This is because a player has to first think of winning before sabotaging. In other words, it may make sense to invest in only productive effort and nothing in sabotage but it never makes sense to invest in only sabotage but invest nothing in productive effort. There is no point in investing in sabotage, if you have no chance of winning.

To obtain proposition 1 , we assumed that $V_{1}-V_{2} \geq V_{2}-V_{3}$. This condition ensures that player 3 will not invest in sabotage because her expected payoff in stage 1 is zero. However, player 3's valuation is increasing in the sabotage effort of player 2. Also, player 2's valuation is increasing in $\Pi_{31}$. Therefore, player 2 derives a benefit from helping player 3 . The reason why player 2 sets $\mathrm{e}_{23}=0$ is because while there are benefits of sabotaging, the cost required to do so is too much. Note also that even though 
player 1's payoff is always positive, it decreases as $\Pi_{31}$ increases but is never zero, given $\mathrm{V}_{1}-\mathrm{V}_{2} \geq \mathrm{V}_{2}-\mathrm{V}_{3}$

\section{Conclusion}

In this paper, we have explored a hitherto uncharted area of research on contests: the sabotage of potential rivals. The only papers which examine sabotage in a model with non-identical players are Chen (2003) and Kräkel (2004). In these models, where players sabotage current rivals, there is always an equilibrium in which someone engages in sabotage. In contrast, in our model, where players sabotage potential rivals there could be a unique equilibrium with no sabotage. We also find that only the most-able player may engage in sabotage and indeed prefers a situation where sabotage is allowed to one where sabotage is banned. While our analysis was based on certain simplifying assumptions, we were still able to obtain interesting results which had not been known in the literature.

There are several possible areas of future research. For example, in proving proposition 1, we had to assume a special condition which simplified the analysis significantly. A possible task for future research is to relax this condition, but it should be noted that this is fairly challenging. Another extension would be to incorporate the sabotage of current rivals in addition to the sabotage of potential rivals in the same model. We could also consider making sabotage permanent. That is, helping a weaker player to win in the semi-final makes this player stronger if she advances to the final.

Moreover, sabotage through a third-party might be more socially acceptable than direct sabotage. For example, people frown upon negative campaign information by a politician against her rival. But positive information about a potential rival's current opponent will not be seen as a negative conduct. Hence direct and indirect sabotage 
might have different social costs and it may be worthwhile to investigate the normative implications of this. In our model, the implicit assumption is that the cost of direct sabotage is infinitely large (i.e., prohibitive).

\section{Appendix A: Proof of Proposition 2}

Groh et al. (2003) show that $\widetilde{\mathrm{E}}_{13}^{\mathrm{s}}=\widetilde{\mathrm{E}}_{24}^{\mathrm{s}}=0$. Applying the result from Baye et al. (1996) yields $\mathrm{E}_{13}^{\mathrm{S}}=\Pi_{31}\left(1+\Pi_{31} / \Pi_{11}\right) / 2$. Inserting the stage 1 valuations from corollary 1 gives $\mathrm{E}_{13}^{\mathrm{S}}=\mathrm{x}(3+\sqrt{2}) /(2+2 \sqrt{2})>0$. Similarly, $\mathrm{E}_{24}^{\mathrm{S}}=\Pi_{21}\left(1+\Pi_{21} / \Pi_{31}\right) / 2=\mathrm{x}(8-5 \sqrt{2}) / 8>0$. This completes the proof of the first part of proposition 2 .

For proving $\mathrm{E}^{\mathrm{F}}<\widetilde{\mathrm{E}}^{\mathrm{F}}$, note that Groh et al. (2003) show $\widetilde{\mathrm{E}}^{\mathrm{F}}=\mathrm{V}_{2}\left(1+\mathrm{V}_{2} / \mathrm{V}_{1}\right) / 2$. In our sabotage equilibrium we obtain

$$
\begin{aligned}
\mathrm{E}^{\mathrm{F}}=\mathrm{p}_{31} \mathrm{p}_{41} \frac{\mathrm{V}_{4}}{2}(1+ & \left.\frac{\mathrm{V}_{4}}{\mathrm{~V}_{3}}\right)+\left(1-\mathrm{p}_{31}\right)\left(1-\mathrm{p}_{41}\right) \frac{\mathrm{V}_{2}}{2}\left(1+\frac{\mathrm{V}_{2}}{\mathrm{~V}_{1}}\right) \\
& +\mathrm{p}_{41}\left(1-\mathrm{p}_{31}\right) \frac{\mathrm{V}_{4}}{2}\left(1+\frac{\mathrm{V}_{4}}{\mathrm{~V}_{1}}\right)+\mathrm{p}_{31}\left(1-\mathrm{p}_{41}\right) \frac{\mathrm{V}_{3}}{2}\left(1+\frac{\mathrm{V}_{3}}{\mathrm{~V}_{2}}\right)
\end{aligned}
$$

We know that $\mathrm{V}_{2}\left(1+\mathrm{V}_{2} / \mathrm{V}_{1}\right) / 2>\mathrm{V}_{4}\left(1+\mathrm{V}_{4} / \mathrm{V}_{1}\right) / 2$, since $\mathrm{V}_{2}>\mathrm{V}_{4}$. Moreover, $\mathrm{a}=\mathrm{b}=\mathrm{c}=\mathrm{x}$ implies $\mathrm{V}_{2}=\mathrm{V}_{1}-\mathrm{x}, \mathrm{V}_{3}=\mathrm{V}_{1}-2 \mathrm{x}$ and $\mathrm{V}_{4}=\mathrm{V}_{1}-3 \mathrm{x} . \mathrm{V}_{4}>0$ requires $\mathrm{V}_{1}>3 \mathrm{x}$. We then obtain after some computations

$$
\frac{\mathrm{V}_{2}}{2}\left(1+\frac{\mathrm{V}_{2}}{\mathrm{~V}_{1}}\right)>\frac{\mathrm{V}_{4}}{2}\left(1+\frac{\mathrm{V}_{4}}{\mathrm{~V}_{3}}\right) \Leftrightarrow 2 \mathrm{~V}_{1}^{2}-4 \mathrm{xV}_{1}-\mathrm{x}^{2}>0
$$

This condition is always satisfied, since due to $V_{1}>3 x$ it can be written as $2 V_{1}^{2}-4 x V_{1}-x^{2}>2 x V_{1}-x^{2}>0$. In the same way, we obtain 


$$
\frac{\mathrm{V}_{2}}{2}\left(1+\frac{\mathrm{V}_{2}}{\mathrm{~V}_{1}}\right)>\frac{\mathrm{V}_{3}}{2}\left(1+\frac{\mathrm{V}_{3}}{\mathrm{~V}_{2}}\right) \Leftrightarrow 2 \mathrm{~V}_{1}^{2}-2 \mathrm{xV}_{1}-\mathrm{x}^{2}>0,
$$

which is always satisfied since $2 V_{1}^{2}-2 x V_{1}-x^{2}>4 x V_{1}-x^{2}>0$. Taking into account these relations as well as $p_{31} p_{41}+\left(1-p_{31}\right)\left(1-p_{41}\right)+p_{41}\left(1-p_{31}\right)+p_{31}\left(1-p_{41}\right)=1$ in (A.1) proves $\mathrm{E}^{\mathrm{F}}<\widetilde{\mathrm{E}}^{\mathrm{F}}$.

To complete the proof, we define $\Delta:=\mathrm{E}_{13}^{\mathrm{S}}+\mathrm{E}_{24}^{\mathrm{S}}+\mathrm{E}^{\mathrm{F}}-\widetilde{\mathrm{E}}_{13}^{\mathrm{S}}-\widetilde{\mathrm{E}}_{24}^{\mathrm{S}}-\widetilde{\mathrm{E}}^{\mathrm{F}}$ and show that $\Delta<0$. Inserting all E's and $\widetilde{E}$ 's yields after some computations

$$
\Delta=\mathrm{x} \frac{-(4+3 \sqrt{2}) \mathrm{V}_{1}^{3}+(20+17 \sqrt{2}) \mathrm{xV}_{1}^{2}-(31+30 \sqrt{2}) \mathrm{x}^{2} \mathrm{~V}_{1}+6(2+3 \sqrt{2}) \mathrm{x}^{3}}{8 \mathrm{~V}_{1}\left(\mathrm{~V}_{1}-2 \mathrm{x}\right)\left(\mathrm{V}_{1}-\mathrm{x}\right)}
$$

The idea of the proof is to take as given $\mathrm{V}_{1}$ and to maximize $\Delta$ with respect to $\mathrm{x}$ subject to the constraint $0<\mathrm{x}<\mathrm{V}_{1} / 3$. Differentiating $\Delta$, it is straightforward to show that $\mathrm{d}^{2} \Delta / \mathrm{dx}^{2}>0$. Hence, $\Delta$ is convex in $\mathrm{x}$ and reaches a maximum either for $\mathrm{x} \rightarrow 0$ or $x \rightarrow V_{1} / 3$. Calculating the limits yields $\lim _{x \rightarrow 0} \Delta=0$ and $\lim _{x \rightarrow V_{1} / 3} \Delta=-V_{1} / 16<0$. Hence, in the relevant range $\Delta$ is always negative as required.

\section{QED}

\section{Appendix B: Proof of Proposition 4}

Suppose we have an equilibrium where at most player 1 invests in sabotage, i.e. $\mathrm{e}_{13} \geq 0$ and all other sabotage efforts are zero. Computing the expected payoffs in the mixedstrategy equilibrium of stage 2 according to (1), we may write the stage 1 valuations of the players as

$$
\begin{aligned}
& \Pi_{11}=\mathrm{p}_{31}\left(\mathrm{~V}_{1}-\mathrm{V}_{3}+\mathrm{k}\right)+\left(1-\mathrm{p}_{31}\right)\left(\mathrm{V}_{1}-\mathrm{V}_{2}+\mathrm{k}\right)=\mathrm{V}_{1}-\mathrm{V}_{2}+\mathrm{p}_{31}\left(\mathrm{~V}_{2}-\mathrm{V}_{3}\right)+\mathrm{k}, \\
& \Pi_{41}=\mathrm{p}_{31} \mathrm{k}+\left(1-\mathrm{p}_{31}\right) \mathrm{k}=\mathrm{k},
\end{aligned}
$$




$$
\begin{aligned}
& \Pi_{21}=\mathrm{p}_{41}\left(\mathrm{~V}_{2}-\mathrm{V}_{4}+\mathrm{k}\right)+\left(1-\mathrm{p}_{41}\right) \mathrm{k}=\mathrm{p}_{41}\left(\mathrm{~V}_{2}-\mathrm{V}_{4}\right)+\mathrm{k}, \\
& \Pi_{31}=\mathrm{p}_{41}\left(\mathrm{~V}_{3}-\mathrm{V}_{4}+\mathrm{k}\right)+\left(1-\mathrm{p}_{41}\right) \mathrm{k}+\mathrm{e}_{13}=\mathrm{p}_{41}\left(\mathrm{~V}_{3}-\mathrm{V}_{4}\right)+\mathrm{k}+\mathrm{e}_{13} .
\end{aligned}
$$

With this insight, we can prove both parts of proposition 4 by contradiction. Consider first part (i). Suppose we have an equilibrium where only player 1 invests in sabotage, i.e. $\mathrm{e}_{13}>0$. Equations (B.1) and (B.2) imply $\Pi_{11}-\Pi_{41}=V_{1}-V_{2}+p_{31}\left(V_{2}-V_{3}\right)>0$. Hence, we only have to distinguish two cases: case 1 with $\Pi_{11}>\Pi_{41}$ and $\Pi_{21} \geq \Pi_{31}$, and case 2 with $\Pi_{11}>\Pi_{41}$ and $\Pi_{31} \geq \Pi_{21}$. According to (B.3) and (B.4), case 1 is possible only if $\mathrm{e}_{13} \leq \mathrm{bp}_{41}$. But $\Pi_{11}>\Pi_{41}$ and the results in Baye et al. (1996) imply

$$
\mathrm{p}_{41}=\frac{\Pi_{41}}{2 \Pi_{11}}=\frac{\mathrm{k}}{2 \mathrm{a}+2 \mathrm{bp}_{31}+2 \mathrm{k}}
$$

Letting $\mathrm{k} \rightarrow 0$ yields $\mathrm{p}_{41}=0$ and, thus, the condition for case 1 is $\mathrm{e}_{13} \leq \mathrm{bp}_{41}=0$. But this contradicts $e_{13}>0$. To put another way, case 1 is only possible for $\mathrm{e}_{13}=0$.

It remains to derive a contradiction in case $2 . \Pi_{11}>\Pi_{41}$ and $\Pi_{21} \leq \Pi_{31}$ now imply

$$
\mathrm{p}_{31}=1-\frac{\Pi_{21}}{2 \Pi_{31}}=\frac{(\mathrm{c}-\mathrm{b}) \mathrm{p}_{41}+2 \mathrm{e}_{13}+\mathrm{k}}{2 \mathrm{c} \mathrm{p}_{41}+2 \mathrm{e}_{13}+2 \mathrm{k}}, \quad \mathrm{p}_{41}=\frac{\Pi_{41}}{2 \Pi_{11}}=\frac{\mathrm{k}}{2 \mathrm{a}+2 \mathrm{~b} \mathrm{p}_{31}+2 \mathrm{k}} .
$$

The fixed point of these equations for $\mathrm{k} \rightarrow 0$ is $\mathrm{p}_{41}=0$ and $\mathrm{p}_{31}=1$. Note that this is true independent of the sabotage effort level. But $\Pi_{11}>\Pi_{41}$ and $\mathrm{p}_{31}=1$ also imply $\Pi_{10}=\mathrm{a}+\mathrm{bp}_{31}-\mathrm{e}_{13}=\mathrm{a}+\mathrm{b}-\mathrm{e}_{13}$ and, thus, $\mathrm{e}_{13}>0$ cannot be an equilibrium: For every $\mathrm{e}_{13}>0$, player 1 has an incentive to reduce $\mathrm{e}_{13}$, since this increases her stage 0 payoff without changing $\mathrm{p}_{31}=1$. This contradiction completes the proof of part (i). 
Let us now turn to part (ii). Suppose we have an equilibrium in which none of the players invest in sabotage so that also $\mathrm{e}_{13}=0$. Then we are back to lemma 2 of Groh et al. (2003), where $\mathrm{p}_{41}=0$ and $\mathrm{p}_{31}=1 / 2$. Player 1 's payoff is $\Pi_{10}=a+b / 2$. Suppose now player 1 deviates from this equilibrium, and invests a small but positive $e_{13}>0$ in sabotage. Then we know from our analysis of part (i) that $p_{31}$ jumps from $1 / 2$ to 1 (remember that for $\mathrm{e}_{13}>0$ only case 2 is possible). For player 1's payoff we then obtain $\Pi_{10}=\mathrm{a}+\mathrm{b}-\mathrm{e}_{13}>\mathrm{a}+\mathrm{b} / 2$, since there always exists a small but positive $\mathrm{e}_{13}$ such that $0<\mathrm{e}_{13}<\mathrm{b} / 2$. Hence, player 1 will deviate from a zero sabotage equilibrium. This proves part (ii) of proposition 4.

\section{QED}

\section{Appendix C: Equilibrium in Seeding $C$ if $V_{1}>V_{2}=V_{3}>V_{4}$}

In this appendix we prove

Proposition 5: Suppose the players' valuations are such that $\mathrm{V}_{1}>\mathrm{V}_{2}=\mathrm{V}_{3}>\mathrm{V}_{4}$ and players 1 and 4 belong to one group and players 2 and 3 belong to another group. Then there exists a unique pure-strategy subgame perfect equilibrium in which no player engages in sabotage.

Suppose first $\Pi_{31} \leq \Pi_{21}$. We know that player 4 never invests in sabotage. Since $V_{2}=V_{3}$ and players 2 and 3 are in the same group, it follows that player 1 will not invest in sabotage. Using the results in Baye et al. (1996), $\Pi_{31} \leq \Pi_{21}$ imply $\Pi_{30}=-\mathrm{e}_{34}$ which, in turn, yields $\mathrm{e}_{34}=0$. For player 2, we obtain 


$$
\Pi_{20}=\Pi_{21}-\Pi_{31}-\mathrm{e}_{24}=\mathrm{bp}_{41}-\mathrm{e}_{24} .
$$

But $V_{2}=V_{3}$ implies $b=0$. Therefore, $e_{24}=0$. Hence, no player invests in sabotage if

$$
\Pi_{31} \leq \Pi_{21} .
$$

Now turn to the case $\Pi_{31} \geq \Pi_{21}$. Again, player 4 will not invest in sabotage and $b=$

0 implies that player 1 will not invest in sabotage. $\Pi_{31} \geq \Pi_{21}$ implies $e_{24}=0$. For player 3, we obtain

$$
\Pi_{30}=\Pi_{31}-\Pi_{21}-\mathrm{e}_{34}=-\mathrm{bp}_{41}-\mathrm{e}_{34}
$$

But $b=0$ implies $e_{34}=0$. Also for $\Pi_{31} \geq \Pi_{21}$ no player invests in sabotage and in both cases, the equilibrium is unique. $\quad$ QED

\section{References}

Amegashie, J.A. (2004). Burning out in sequential elimination contests. available at http://www.uoguelph.ca/ jamegash/Burning_out.pdf

Amegashie, J.A. (1999). The design of rent-seeking competitions: committees, preliminary and final contests. Public Choice 99: 63-72.

Auriol, E., Friebel, G., and Pechlivanos, L. (2002). Career Concerns in Teams. Journal of Labor Economics 20: 289-307.

Baye, M.R., Kovenock, D., and de Vries, C.G. (1996). The all-pay auction with complete information. Economic Theory 8: 291-305.

Chen, K-P. (2003). Sabotage in Promotion Tournaments. Journal of Law, Economics and Organization 19: 119-40.

Gradstein, M., and Konrad, K.A. (1999). Orchestrating rent- seeking contests. Economic Journal 109: 536-545.

Groh, C., Moldovanu, B., Sela, A., and Sunde, U. (2003). Optimal seedings in elimination tournaments. Discussion paper, University of Bonn. 
Hillman, A.L., and Riley, J. (1989). Politically contestable rents and transfers. Economics and Politics 1: 17-39.

Konrad, K. A. (1999). Sabotage in Rent-Seeking Contests. Journal of Law, Economics, and Organization 16: 155-65.

Kräkel, M. (2004). Helping and sabotaging in tournaments. International Game Theory Review, forthcoming.

Lazear, E.P. (1989). Pay equality and industrial politics. Journal of Political Economy 97: 561-580.

Rosen, S. (1986). Incentives in elimination tournaments. American Economic Review 76: 701-715.

Skarpedas, S., and Grofman, B. (1995). Modelling negative campaigning. American Political Science Review 89: 49-61. 


\section{CESifo Working Paper Series}

(for full list see www.cesifo-group.de)

1433 George Economides and Apostolis Philippopoulos, Should Green Governments Give Priority to Environmental Policies over Growth-Enhancing Policies?, March 2005

1434 George W. Evans and Seppo Honkapohja, An Interview with Thomas J. Sargent, March 2005

1435 Helge Berger and Volker Nitsch, Zooming Out: The Trade Effect of the Euro in Historical Perspective, March 2005

1436 Marc-Andreas Muendler, Rational Information Choice in Financial Market Equilibrium, March 2005

1437 Martin Kolmar and Volker Meier, Intra-Generational Externalities and InterGenerational Transfers, March 2005

1438 M. Hashem Pesaran and Takashi Yamagata, Testing Slope Homogeneity in Large Panels, March 2005

1439 Gjermund Nese and Odd Rune Straume, Industry Concentration and Strategic Trade Policy in Successive Oligopoly, April 2005

1440 Tomer Blumkin and Efraim Sadka, A Case for Taxing Education, April 2005

1441 John Whalley, Globalization and Values, April 2005

1442 Denise L. Mauzerall, Babar Sultan, Namsoug Kim and David F. Bradford, Charging $\mathrm{NO}_{x}$ Emitters for Health Damages: An Exploratory Analysis, April 2005

1443 Britta Hamburg, Mathias Hoffmann and Joachim Keller, Consumption, Wealth and Business Cycles in Germany, April 2005

1444 Kohei Daido and Hideshi Itoh, The Pygmalion Effect: An Agency Model with Reference Dependent Preferences, April 2005

1445 John Whalley, Rationality, Irrationality and Economic Cognition, April 2005

1446 Henning Bohn, The Sustainability of Fiscal Policy in the United States, April 2005

1447 Torben M. Andersen, Is there a Role for an Active Fiscal Stabilization Policy? April 2005

1448 Hans Gersbach and Hans Haller, Bargaining Power and Equilibrium Consumption, April 2005 
1449 Jerome L. Stein, The Transition Economies: A NATREX Evaluation of Research, April 2005

1450 Raymond Riezman, John Whalley and Shunming Zhang, Metrics Capturing the Degree to which Individual Economies are Globalized, April 2005

1451 Romain Ranciere, Aaron Tornell and Frank Westermann, Systemic Crises and Growth, April 2005

1452 Plutarchos Sakellaris and Focco W. Vijselaar, Capital Quality Improvement and the Sources of Growth in the Euro Area, April 2005

1453 Kevin Milligan and Michael Smart, Regional Grants as Pork Barrel Politics, April 2005

1454 Panu Poutvaara and Andreas Wagener, To Draft or not to Draft? Efficiency, Generational Incidence, and Political Economy of Military Conscription, April 2005

1455 Maurice Kugler and Hillel Rapoport, Skilled Emigration, Business Networks and Foreign Direct Investment, April 2005

1456 Yin-Wong Cheung and Eiji Fujii, Cross-Country Relative Price Volatility: Effects of Market Structure, April 2005

1457 Margarita Katsimi and Thomas Moutos, Inequality and Relative Reliance on Tariffs: Theory and Evidence, April 2005

1458 Monika Bütler, Olivia Huguenin and Federica Teppa, Why Forcing People to Save for Retirement may Backfire, April 2005

1459 Jos Jansen, The Effects of Disclosure Regulation of an Innovative Firm, April 2005

1460 Helge Bennmarker, Kenneth Carling and Bertil Holmlund, Do Benefit Hikes Damage Job Finding? Evidence from Swedish Unemployment Insurance Reforms, May 2005

1461 Steffen Huck, Kai A. Konrad and Wieland Müller, Merger without Cost Advantages, May 2005

1462 Louis Eeckhoudt and Harris Schlesinger, Putting Risk in its Proper Place, May 2005

1463 Hui Huang, John Whalley and Shunming Zhang, Trade Liberalization in a Joint Spatial Inter-Temporal Trade Model, May 2005

1464 Mikael Priks, Optimal Rent Extraction in Pre-Industrial England and France - Default Risk and Monitoring Costs, May 2005

1465 François Ortalo-Magné and Sven Rady, Heterogeneity within Communities: A Stochastic Model with Tenure Choice, May 2005

1466 Jukka Pirttilä and Sanna Tenhunen, Pawns and Queens Revisited: Public Provision of Private Goods when Individuals make Mistakes, May 2005 
1467 Ernst Fehr, Susanne Kremhelmer and Klaus M. Schmidt, Fairness and the Optimal Allocation of Ownership Rights, May 2005

1468 Bruno S. Frey, Knight Fever - Towards an Economics of Awards, May 2005

1469 Torberg Falch and Marte Rønning, The Influence of Student Achievement on Teacher Turnover, May 2005

1470 John Komlos and Peter Salamon, The Poverty of Growth with Interdependent Utility Functions, May 2005

1471 Hui Huang, Yi Wang, Yiming Wang, John Whalley and Shunming Zhang, A Trade Model with an Optimal Exchange Rate Motivated by Current Discussion of a Chinese Renminbi Float, May 2005

1472 Helge Holden, Lars Holden and Steinar Holden, Contract Adjustment under Uncertainty, May 2005

1473 Kai A. Konrad, Silent Interests and All-Pay Auctions, May 2005

1474 Ingo Vogelsang, Electricity Transmission Pricing and Performance-Based Regulation, May 2005

1475 Spiros Bougheas and Raymond Riezman, Trade and the Distribution of Human Capital, June 2005

1476 Vesa Kanniainen, Seppo Kari and Jouko Ylä-Liedenpohja, The Start-Up and Growth Stages in Enterprise Formation: The "New View" of Dividend Taxation Reconsidered, June 2005

1477 M. Hashem Pesaran, L. Vanessa Smith and Ron P. Smith, What if the UK had Joined the Euro in 1999? An Empirical Evaluation Using a Global VAR, June 2005

1478 Chang Woon Nam and Doina Maria Radulescu, Effects of Corporate Tax Reforms on SMEs' Investment Decisions under the Particular Consideration of Inflation, June 2005

1479 Panos Hatzipanayotou, Sajal Lahiri and Michael S. Michael, Globalization, CrossBorder Pollution and Welfare, June 2005

1480 John Whalley, Pitfalls in the Use of Ad valorem Equivalent Representations of the Trade Impacts of Domestic Policies, June 2005

1481 Edward B. Barbier and Michael Rauscher, Trade and Development in a Labor Surplus Economy, June 2005

1482 Harrie A. A. Verbon and Cees A. Withagen, Tradable Emission Permits in a Federal System, June 2005

1483 Hendrik Hakenes and Andreas Irmen, On the Long-Run Evolution of Technological Knowledge, June 2005 
1484 Nicolas Schmitt and Antoine Soubeyran, A Simple Model of Brain Circulation, June 2005

1485 Carsten Hefeker, Uncertainty, Wage Setting and Decision Making in a Monetary Union, June 2005

1486 Ondřej Schneider and Jan Zápal, Fiscal Policy in New EU Member States - Go East, Prudent Man!, June 2005

1487 Christian Schultz, Virtual Capacity and Competition, June 2005

1488 Yvan Lengwiler and Elmar Wolfstetter, Bid Rigging - An Analysis of Corruption in Auctions, June 2005

1489 Johannes Becker and Clemens Fuest, Does Germany Collect Revenue from Taxing Capital Income?, June 2005

1490 Axel Dreher and Panu Poutvaara, Student Flows and Migration: An Empirical Analysis, June 2005

1491 Bernd Huber and Marco Runkel, Interregional Redistribution and Budget Institutions under Asymmetric Information, June 2005

1492 Guido Tabellini, Culture and Institutions: Economic Development in the Regions of Europe, July 2005

1493 Kurt R. Brekke and Michael Kuhn, Direct to Consumer Advertising in Pharmaceutical Markets, July 2005

1494 Martín Gonzalez-Eiras and Dirk Niepelt, Sustaining Social Security, July 2005

1495 Alfons J. Weichenrieder, (Why) Do we need Corporate Taxation?, July 2005

1496 Paolo M. Panteghini, S-Based Taxation under Default Risk, July 2005

1497 Panos Hatzipanayotou and Michael S. Michael, Migration, Tied Foreign Aid and the Welfare State, July 2005

1498 Agata Antkiewicz and John Whalley, BRICSAM and the Non-WTO, July 2005

1499 Petr Hedbávný, Ondřej Schneider and Jan Zápal, A Fiscal Rule that has Teeth: A Suggestion for a 'Fiscal Sustainability Council' underpinned by the Financial Markets, July 2005

1500 J. Atsu Amegashie and Marco Runkel, Sabotaging Potential Rivals, July 2005 